\title{
Fructus Corni extract-induced neuritogenesis in PC12 cells is associated with the suppression of stromal interaction molecule 1 expression and inhibition of $\mathrm{Ca}^{2+}$ influx
}

\author{
XUSHI WANG ${ }^{1}$, JIAQI LIU ${ }^{1}$, NA JIN ${ }^{1}$, DAN XU ${ }^{1}$, JUNYU WANG ${ }^{1}$, YONGMING HAN ${ }^{2}$ and NINA YIN ${ }^{2}$ \\ ${ }^{1}$ Department of Oncology, Xinhua Hospital of Hubei, Wuhan, Hubei 430015; ${ }^{2}$ Department of Anatomy, \\ College of Basic Medical Sciences, Hubei University of Chinese Medicine, Wuhan, Hubei 430065, P.R. China
}

Received June 26, 2014; Accepted February 13, 2015

DOI: $10.3892 /$ etm.2015.2316

\begin{abstract}
Fructus Corni (Cornus officinalis Sieb. et Zucc.) is commonly prescribed as a traditional Chinese herbal medicine that possesses pharmacological actions against inflammation, diabetic nephropathy, tumors, oxidation and aging. However, its function and mode of action within the nervous system remain largely unclear. In this study, the effects of Fructus Corni extract (FCE) on neuronal differentiation were investigated. It was found that FCE significantly increased the percentage of $\mathrm{PC} 12$ cells bearing neurites $(\mathrm{P}<0.001)$. Following the generation of neurite outgrowth, FCE treatment decreased the mRNA expression of stromal interaction molecule 1 (STIM1; $\mathrm{P}<0.05)$ and suppressed the expression of STIM1 protein $(\mathrm{P}<0.001)$. In addition, extracellular calcium $\left(\mathrm{Ca}^{2+}\right)$ influx was inhibited resulting in a reduction in the intracellular $\mathrm{Ca}^{2+}$ level, suggesting that the inhibition of $\mathrm{Ca}^{2+}$ influx may be involved in the FCE-promoted neurite outgrowth of PC12 cells. These results demonstrate that FCE induces neurite outgrowth in $\mathrm{PC} 12$ cells and that this is associated with the suppression of STIM1 expression and the inhibition of $\mathrm{Ca}^{2+}$ influx, which may partially explain the FCE-induced neuritogenesis.
\end{abstract}

Correspondence to: Dr Nina Yin, Department of Anatomy, College of Basic Medical Sciences, Hubei University of Chinese Medicine, 1 West Road of Huangjia Lake, Wuhan, Hubei 430065, P.R. China

E-mail: yinnina-hbtcm@hotmail.com

Abbreviations: FCE, Fructus Corni extract; NGF, nerve growth factor; MTT, 3-(4,5-dimethylthiazol-2-yl)-2,5-diphenyltetrazolium; DMSO, dimethyl sulfoxide; SOCE, store-operated $\mathrm{Ca}^{2+}$ entry; ER, endoplasmic reticulum; STIM1, stromal interaction molecule 1; CRAC, $\mathrm{Ca}_{2}{ }^{+}$release-activated $\mathrm{Ca}_{2}^{+}$; VGCC, voltage-gated $\mathrm{Ca}^{2+}$ channel; IP3, inositol 1,4,5-trisphosphate; TRPC, transient receptor potential channel

Key words: Fructus Corni extract, neurite outgrowth, STIM1, $\mathrm{Ca}^{2+}$ influx, PC12 cells

\section{Introduction}

Calcium $\left(\mathrm{Ca}^{2+}\right)$ is a ubiquitous and essential second messenger in cells, which mediates a broad of cellular functions including secretion, excitation, contraction, metabolism, transcription, growth, proliferation, division and apoptosis (1). In general, $\mathrm{Ca}^{2+}$ signals are controlled by $\mathrm{Ca}^{2+}$ flux in (influx) and out (efflux) through plasma membrane channels in order to achieve $\mathrm{Ca}^{2+}$ homeostasis within the cell (2). Store-operated $\mathrm{Ca}^{2+}$ entry (SOCE) is a major mechanism of $\mathrm{Ca}^{2+}$ import from extracellular to intracellular space, which has been demonstrated to consistently increase intracellular $\mathrm{Ca}^{2+}$ levels (3).

Recently, two key factors involved in SOCE have been identified. These are the endoplasmic reticulum (ER) $\mathrm{Ca}^{2+}$ sensor protein stromal interaction molecule 1 (STIM1) and the plasma membrane $\mathrm{Ca}^{2+}$ channel protein Orail (4). STIM1 is a transmembrane protein located in the ER where it has a $\mathrm{Ca}^{2+}$ sensor function, and it has a $\mathrm{Ca}^{2+}$-binding EF-hand motif located within the ER lumen (5). Orail is an essential component of $\mathrm{Ca}^{2+}$ release-activated $\mathrm{Ca}^{2+}$ (CRAC) channels in the plasma membrane (6). STIM1 is predominantly located in the ER lumina, the main intracellular $\mathrm{Ca}^{2+}$ store. When the store of $\mathrm{Ca}^{2+}$ is depleted and inositol 1,4,5-trisphosphate (IP3) receptors are activated, STIM1 translocates into ER/plasma membrane junctions where it couples to activate Orail and, possibly, transient receptor potential channels (TRPCs). At these junctions, STIM proteins bind to and activate the highly $\mathrm{Ca}^{2+}$-selective Orai channels, thereby mediating finely controlled $\mathrm{Ca}^{2+}$ signals and homeostatically balancing cellular $\mathrm{Ca}^{2+}$ levels $(7,8)$.

The traditional Chinese herbal medicine Fructus Corni (Cornus officinalis Sieb. et Zucc.), known as Shan-zhu-yu in Chinese, has a long history of use in the treatment of diabetes, cancer, inflammation and shock, and for hepatoprotection (9). Fructus Corni contains gallic acid, malic acid, tartaric acid, ursolic acid, morroniside, loganin and sweroside $(10,11)$. Recent studies have shown Fructus Corni extract (FCE) to be effective against cerebral ischemia-reperfusion injury, and to have anti-oxidant and anti-aging functions (12-14). However, its role and effect in the nervous system remain unknown.

In the present study, the aim was to investigate the effects of FCE on neuronal differentiation. The effects of 
FCE treatment on neurite outgrowth, intracellular $\mathrm{Ca}^{2+}$ and the expression of STIM1 provide useful information to the therapeutic potential of FCE in neurodegenerative diseases.

\section{Materials and methods}

Preparation of FCE. Fresh Fructus Corni (C. officinalis Sieb. et Zucc.) was purchased from Tong Ren Tang (Beijing, China). The Fructus Corni (100 g) was extracted by heating in $1,000 \mathrm{ml}$ distilled water at $80^{\circ} \mathrm{C}$ for $2 \mathrm{~h}$, and then concentrated using a rotary evaporator (Rotary evaporator R-480; Büchi Labortechnik AG, Flawil, Switzerland). The concentrated extracts were lyophilized using a freeze dryer (FDU-540; Elaya, Tokyo, Japan). Following the lyophilization, a powder was obtained (yield, $25.82 \mathrm{~g}$ ) and was dissolved in dimethyl sulfoxide (DMSO; Sigma-Aldrich, St. Louis, MO, USA) to provide a stock solution of concentration $100 \mathrm{mg} / \mathrm{ml}$ and stored at $4^{\circ} \mathrm{C}$. The stock solution of FCE was then diluted with medium to the desired concentration prior to use.

Materials. Rat $\beta$-nerve growth factor (NGF) was purchased from R\&D Systems (Minneapolis, MN, USA). 3-(4,5-Dimethylthiazol-2-yl)-2,5-diphenyltetrazolium (MTT) was obtained from Sigma-Aldrich. Rabbit polyclonal anti-STIM1 (S6072) and mouse monoclonal anti- $\beta$-actin (A5316) antibodies were purchased from Sigma-Aldrich.

Cell culture. PC12 (adrenal gland pheochromocytoma) cells (that were a gift from Professor Yanhong Liao of Huazhong University of Science and Technology, Wuhan, China) were cultured in Dulbecco's modified Eagle's medium (DMEM; Hyclone $^{\mathrm{TM}}$, GE Healthcare, Logan, UT, USA) supplemented with $10 \%$ heat-inactivated horse serum (Gibco, Grand Island, NY, USA), 5\% heat-inactivated fetal bovine serum (Gibco), and antibiotics $(100 \mu \mathrm{g} / \mathrm{ml}$ streptomycin and $100 \mathrm{U} / \mathrm{ml}$ penicillin; Gibco) at $37^{\circ} \mathrm{C}$ in a $5 \% \mathrm{CO}_{2}$ incubator. Cells were supplied with fresh medium three times per week, and were split at a 1:3 ratio twice per week.

MTT assay. PC12 cells were seeded into 96-well plates (200 $\mu \mathrm{l} /$ well) at a density of $5 \times 10^{4}$ cells $/ \mathrm{ml}$. They were treated with various concentrations $(0,10,20,40,60,80$ and $100 \mu \mathrm{g} / \mathrm{ml}$ ) of FCE for $48 \mathrm{~h}$. At the end of the drug incubation period, MTT (Sigma-Aldrich) working solution $(0.5 \mathrm{mg} / \mathrm{ml})$ was added to each well, and the plates incubated for an additional $4 \mathrm{~h}$ at $37^{\circ} \mathrm{C}$. Following centrifugation at $350 \mathrm{x} \mathrm{g}$ for 5 min, the medium was replaced with DMSO. The absorbance of reduced MTT at $570 \mathrm{~nm}$ was measured with a plate reader (Bio-Rad Laboratories, Hercules, CA, USA). The rate of inhibition of cell proliferation was calculated from the optical density (OD) values as follows: Inhibitory rate of PC12 cell proliferation $(\%)=(\mathrm{OD}$ value control group $-\mathrm{OD}$ value test group) $x$ 100/OD value control group. Based on the $\mathrm{IC}_{50}$ of FCE in PC12 cells, a single concentration of $60 \mu \mathrm{g} / \mathrm{ml}$ was determined according to the results and it was selected for evaluation in the following tests. The MTT assay was also conducted using $60 \mu \mathrm{g} / \mathrm{ml} \mathrm{FCE}$ with various incubation times $(0,1,6,12,18,24,48$ and $72 \mathrm{~h})$ to evaluate whether the effect of FCE was time-dependent. Based on the results a 48-h culture time was used for the PC12 cells treated in different groups.
Lentivirus-delivered RNA interference. Lentiviral plasmids carrying STIM1 short hairpin RNA (shRNA) were purchased from Sigma-Aldrich. The lentivirus was produced by the Hope Center Viral Vectors Core of Washington University (St. Louis, MO, USA). For control infection, non-targeted shRNA was used.

Transduction of shRNA. STIM1 shRNA and non-targeted shRNA were transduced into PC12 cells using lentivirus (Hope Center Viral Vectors Core of Washington University) according to the instructions provided by the manufacturer. Briefly, PC12 cells were infected with lentivirus at day 8 in vitro, and selected with puromycin dihydrochloride (Santa Cruz Biotechnology, Inc.) for 1 week. At 3 days after infection, western blotting or immunofluorescence staining was performed.

Evaluation of neurite outgrowth. PC12 cells ( $1 \times 10^{5}$ cells $\left./ \mathrm{ml}\right)$ were seeded onto 24-well plates and cultured for 1 day, after which time $60 \mu \mathrm{g} / \mathrm{ml} \mathrm{FCE}$ or $50 \mathrm{ng} / \mathrm{ml} \mathrm{NGF}$ was added and the cells were cultured for an additional 2 days. The cells were then fixed with $4 \%$ paraformaldehyde (Sigma-Aldrich) in phosphate-buffered saline (PBS), and cell morphology was assessed under a phase-contrast microscope (IBE2003; Chongqing COIC Industrial Co., Ltd, Chongqing, China). STIM1 shRNA-treated cells were also cultured and assessed, without $60 \mu \mathrm{g} / \mathrm{ml} \mathrm{FCE}$ or $50 \mathrm{ng} / \mathrm{ml}$ NGF addition. Neurite extension from the PC12 cells was regarded as an index of neuronal differentiation. Processes with a length equivalent to $\geq 1$ diameters of the cell body were regarded as neurites. The differentiation of PC12 cells was evaluated by examining the proportion of neurite-bearing cells to total cells in randomly selected fields. The mean differentiation score was obtained for $>100$ PC12 cells in each well. In certain experiments, images of the cells were captured, and the total length of the neurite extension per positive cell and average length of neurites in positive cells were determined in randomly chosen fields using Motic Images Plus software (version 2.0S; Motic Instruments Inc., Richmond, Canada).

Immunofluorescence staining. Cells were blocked with $0.1 \%$ Tween-20 and 5\% goat serum in PBS for $30 \mathrm{~min}$ and then stained for $2 \mathrm{~h}$ at room temperature with monoclonal mouse anti-Myc-Cy3 (1:200, cat. SAB4700448, Sigma-Aldrich) and polyclonal rabbit anti-GAP-43 (1:50, cat. BA0878, Boster, Pleasanton, CA, USA) antibodies. Primary antibody was then visualized using ECL ${ }^{\mathrm{TM}}$ donkey monoclonal anti-rabbit secondary antibody (1:1,000, cat. A-21206, Thermo Fisher Scientific Inc., Waltham, MA, USA). Fluorescent images were captured with a confocal microscope (Olympus Fluoview 500; Olympus, Tokyo, Japan).

Reverse transcription-quantitative polymerase chain reaction $(R T-q P C R)$. Total RNA was extracted using TRIzol reagent (Invitrogen Life Technologies, Carlsbad, CA, USA) and reverse transcribed using M-MLV-Reverse Transcriptase (Promega Corporation, Madison, WI, USA), according to the manufacturer's instructions. qPCR was performed using the SYBR-Green Master PCR mix (Applied Biosystems, Foster City, CA, USA) on the TP800 Real Time PCR System 
A

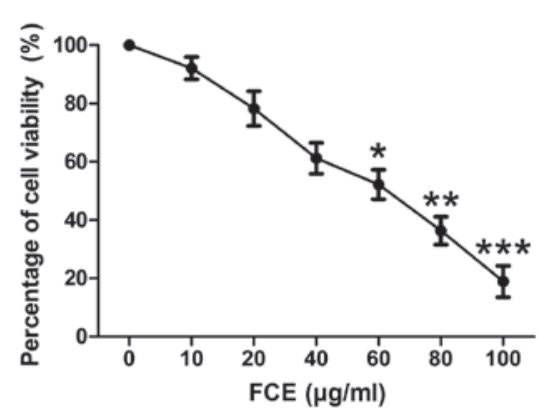

B

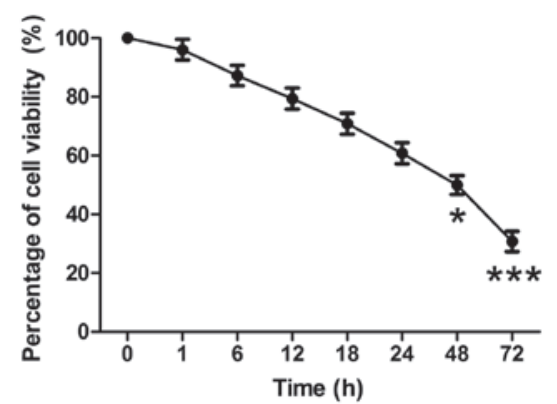

Figure 1. Effects of FCE on PC12 cell viability. PC12 cells were seeded in a 96-well plate at an initial density of 1x10 4 cells/well, and were (A) incubated with various concentrations of FCE for $48 \mathrm{~h}$ or (B) incubated with $60 \mu \mathrm{g} / \mathrm{ml} \mathrm{FCE}$ for various periods of time. Cell viability was determined by MTT assay. The data are presented as a percentage of the vehicle treated control \pm standard error of the mean of three independent experiments. A Student's t-test was used for the determination of significance. ${ }^{*} \mathrm{P}<0.05,{ }^{* *} \mathrm{P}<0.01$ and ${ }^{* * *} \mathrm{P}<0.001$ compared with the untreated control. FCE, Fructus Corni extract; MTT, 3-(4,5-dimethylthiazol-2-yl)-2,5-diphenyltetrazolium.

(Takara Bio, Otsu, Japan). qPCR of cDNA was performed using the following forward $(\mathrm{F})$ and reverse $(\mathrm{R})$ primer sequences: STIM1: F, 5'-GGACGATGATGCCAATGG TGATGT-3'; R, 5'-TTCCACAGGTCCTCCACGCTGAT-3'; $\beta$-actin: F, 5'-TGGACATCCGCAAAGAC-3'; R, 5'-GAA AGGGTGTAACGCAACTA-3'. The amplification conditions were: $5 \mathrm{~min}$ at $94^{\circ} \mathrm{C} ; 35$ cycles of $45 \mathrm{sec}$ at $94^{\circ} \mathrm{C}, 1 \mathrm{~min}$ at $56^{\circ} \mathrm{C}$ and $1 \mathrm{~min}$ at $72^{\circ} \mathrm{C}$; followed by $10 \mathrm{~min}$ at $72^{\circ} \mathrm{C}$. All quantification was normalized to an endogenous gene, $\beta$-actin. For relative quantification, $2^{-(\mathrm{Ct}-\mathrm{Cc})}$ where $\mathrm{Ct}$ and $\mathrm{Cc}$ are the mean threshold cycle differences after normalizing to $\beta$-actin, was calculated and used as an indication of the relative expression levels (15).

Western blotting. PC12 cells were collected, washed once with ice-cold PBS, and lysed with a lysis buffer $(50 \mathrm{mM}$ Tris $\mathrm{HCl}$ $\mathrm{pH} 7.5,150 \mathrm{mM} \mathrm{NaCl}, 1 \mathrm{mM}$ EDTA, $0.1 \%$ SDS, $0.2 \%$ deoxycholic acid and 1:100 protease inhibitor cocktail). Lysates were centrifuged for $10 \mathrm{~min}$ at $12,000 \mathrm{x} \mathrm{g}$ and supernatants were analyzed for protein concentration using a BCA Protein Assay kit (Pierce Biotechnology, Inc., Rockford, IL, USA). Equal amounts of proteins were resolved by SDS-PAGE, transferred to polyvinylidene difluoride membranes, and probed with antibodies against STIM1 $(1: 1,000)$ and $\beta$-actin $(1: 1,000)$, respectively. Immunoreactive bands were visualized by enhanced chemiluminescence. Images of the bands were captured using a scanner (HP Scanjet 7400C; Hewlett-Packard, Palo Alto, CA, USA), and the intensities of the were quantified using Image $\mathbf{J}$ software (National Institutes of Health, Bethesda, MD, USA).

Intracellular $\mathrm{Ca}^{2+}$ measurements. Ratiometric imaging of intracellular $\mathrm{Ca}^{2+}$ using cells loaded with fura-2 was measured as previously described (16). All cells for these experiments were grown in round coverslips $(30 \mathrm{~mm})$ under normal tissue culture conditions, except where specified. Coverslips with cells were placed in a cation-safe solution composed of (in mM): $107 \mathrm{NaCl}, 7.2 \mathrm{KCl}, 1.2 \mathrm{MgCl}_{2}, 11.5$ glucose and 20 HEPES-NaOH pH 7.3, and loaded with fura-2-acetoxymethyl ester ( $2 \mu \mathrm{M}$ final concentration) for $30 \mathrm{~min}$ at $37^{\circ} \mathrm{C}$. Cells were washed, and de-esterification was allowed for a minimum of $15 \mathrm{~min}$. $\mathrm{Ca}^{2+}$ measurements were made using a Leica DMI6000 B fluorescence microscope
(Leica Microsystems, Wetzlar, Germany) controlled by SlideBook software (Intelligent Imaging Innovations, Denver, CO, USA). Fluorescence emission at $505 \mathrm{~nm}$ was monitored while excitation wavelengths were alternated between 340 and $380 \mathrm{~nm}$ at a frequency of $0.5 \mathrm{~Hz}$; intracellular $\mathrm{Ca}^{2+}$ measurements were determined as a $340 / 380 \mathrm{~nm}$ ratio obtained from groups $(n=15-25)$ of single cells. External solutions were (in mM): $135 \mathrm{NaCl}, 5.4 \mathrm{KCl}, 10 \mathrm{HEPES}, 0.02 \mathrm{NaH}_{2} \mathrm{PO}_{4}, 2 \mathrm{Mg}^{2+}$ and 10 glucose $\mathrm{pH}$ 7.4. Measurements shown are representative of a minimum of three independent experiments.

Statistical analysis. All results are expressed as the means \pm standard error of the mean of data obtained from triplicate experiments. Data in two groups were analyzed by Student's t-test. Multiple comparisons of the data were performed by analysis of variance followed by Tukey's test. All the analyses were performed using the SPSS software package, version 17.0 (SPSS, Inc., Chicago, IL, USA). Differences with $\mathrm{P}<0.05$ were considered statistically significant.

\section{Results}

FCE treatment inhibits the proliferation of PC12 cells. To examine the effects of FCE treatment on cell proliferation, MTT assays were used to detect the viability of PC12 cells. When the PC12 cells were treated with various concentrations of FCE for $48 \mathrm{~h}$, the proliferation of PC12 cells was inhibited in a concentration-dependent manner (Fig. 1A). According to the inhibitory rates of FCE at different concentrations on PC12 cells (data not shown), the $\mathrm{IC}_{50}$ was $58.248 \mu \mathrm{g} / \mathrm{ml}$. A concentration of $60 \mu \mathrm{g} / \mathrm{ml} \mathrm{FCE} \mathrm{was} \mathrm{selected} \mathrm{for} \mathrm{use} \mathrm{in} \mathrm{this} \mathrm{study.}$ Furthermore, a time-dependent reduction in cell viability was observed (Fig. 1B). The PC12 cells were incubated for $48 \mathrm{~h}$ with different treatments prior to the following experiments.

FCE treatment induces neurite outgrowth in PC12 cells. Following treatment with $60 \mu \mathrm{g} / \mathrm{ml}$ FCE, morphological changes indicating neurite outgrowth were observed in the PC12 cells (Fig. 2A). NGF, a prominent neurotrophic factor, was used to induce neurite outgrowth in PC12 cells as a positive control. In addition, the morphological changes induced by the knockdown of STIM1 expression with specifically targeted shRNA were observed to elucidate the effect of 
A

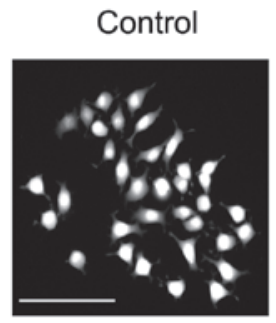

B

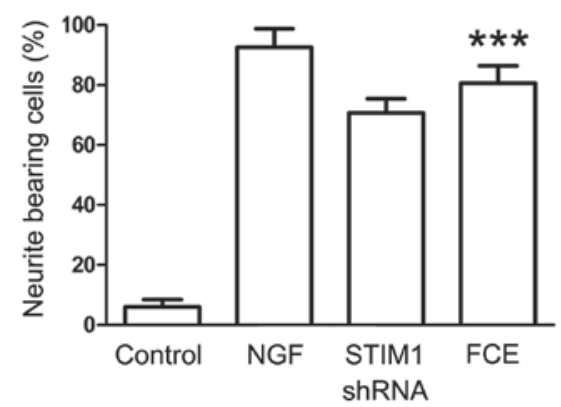

STIM1 ShRNA
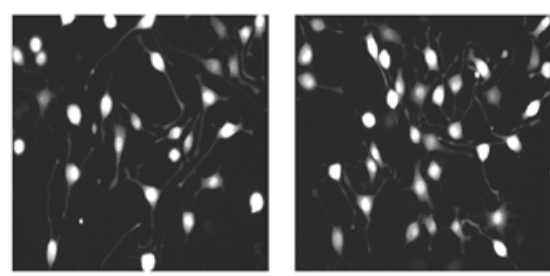

$\mathbf{C}$

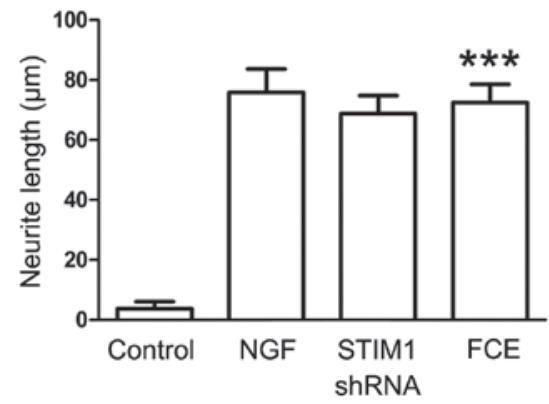

Figure 2. Effects of FCE on neurite outgrowth from PC12 cells. PC12 cells (1x10 cells/ml) were seeded onto 24 -well plates. After 24 h of stabilization, NGF or FCE was added and the cells were cultured for an additional $48 \mathrm{~h}$. STIM1 shRNA-treated PC12 cells were also observed. (A) Morphological observations of PC12 cells from the different groups (control, $50 \mathrm{ng} / \mathrm{ml}$ NGF-treated, STIM1 shRNA-treated and $60 \mu \mathrm{g} / \mathrm{ml} \mathrm{FCE-treated} \mathrm{groups).} \mathrm{Scale} \mathrm{bar,} 100 \mu \mathrm{m}$. (B) The percentage of neurite-bearing cells was calculated from 5 random fields per well, and the data are expressed as a mean percentage of 6 wells in a representative experiment. Data are presented as mean \pm standard error of the mean (SEM). ${ }^{* * *} \mathrm{P}<0.001$ compared with the control group. (C) Neurite lengths in PC12 cells of the various groups were calculated. Data are presented as mean \pm SEM. ${ }^{* * *} \mathrm{P}<0.001$ compared with the untreated control. FCE, Fructus Corni extract; NGF, nerve growth factor; STIM1, stromal interaction molecule 1; shRNA, short hairpin RNA.

STIM1 on neurite outgrowth from PC12 cells. The results demonstrated that FCE treatment stimulated neurite extension in PC12 cells in a similar manner to NGF. In addition, neurite outgrowth from the PC12 cells also was observed in the STIM1 shRNA-treated group, suggesting that STIM1 may be involved in the process of neural differentiation (Fig. 2A). Furthermore, FCE significantly increased the percentage of neurite-bearing cells and the length of the branches (Fig. 2B and C).

FCE treatment suppresses the expression of STIM1 mRNA and protein in PC12 cells. SOCCs, including STIM1, play a important role in cellular proliferation and differentiation. In this study, the knockdown of STIM1 expression with specifically targeted shRNA was carried out, and it effectively reduced the expression of STIM1 mRNA (Fig. 3) and protein (Fig. 4B). Treatment with FCE also reduced the mRNA expression of STIM1 in the PC12 cells (Fig. 3), concurrently with its inducing effect on neurite outgrowth. Immunofluorescence staining confirmed that FCE treatment suppressed the expression of STIM1 protein in PC12 cells (Fig. 4A). Consistent with these results, the expression of STIM1 protein was also found to be significantly decreased in the FCE treatment group compared with the control group by western blot assay (Fig. 4C).

Inhibition of extracellular $\mathrm{Ca}^{2+}$ influx is involved in FCE-induced neurite growth. To examine whether sustained $\mathrm{Ca}^{2+}$ influx is critical for neurite growth in PC12 cells with FCE treatment, cytosolic $\mathrm{Ca}^{2+}$ was measured by the fura 2 assay (Fig. 5). FCE treatment inhibited $\mathrm{Ca}^{2+}$ influx in a time-dependent manner in $\mathrm{PC} 12$ cells, which differed from the NGF and STIM1 shRNA groups. These results suggest that

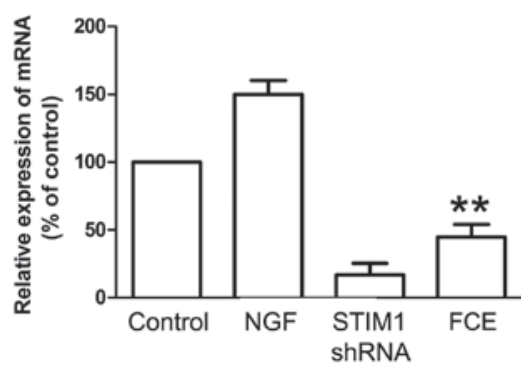

Figure 3. FCE treatment reduces the expression of STIM1 mRNA in PC12 cells. The relative mRNA level of STIM1 expression in PC12 cells of different groups (control, $50 \mathrm{ng} / \mathrm{ml}$ NGF-treated, STIM1 shRNA-treated and $60 \mu \mathrm{g} / \mathrm{ml} \mathrm{FCE}$-treated groups) was measured by reverse transcription-quantitative polymerase chain reaction. Data are presented as mean \pm standard error of the mean from three experiments. ${ }^{* *} \mathrm{P}<0.05$, comparison with the untreated control. FCE, Fructus Corni extract; NGF, nerve growth factor; STIM1, stromal interaction molecule 1; shRNA, short hairpin RNA.

FCE-induced neurite growth may involve a signaling pathway and mechanism different from that of NGF.

\section{Discussion}

In the present study, it was shown that FCE promotes neurite outgrowth and differentiation of PC12 cells. Notably, the FCE-induced neuritogenesis was demonstrated to be associated with the downregulation of STIM1 expression at the mRNA and protein levels, as well as the inhibition of extracellular $\mathrm{Ca}^{2+}$ influx.

The second messenger $\mathrm{Ca}^{2+}$ plays a crucial role in regulating a number of different cellular processes by modulating 
A

Control

NGF

STIM1 shRNA

B
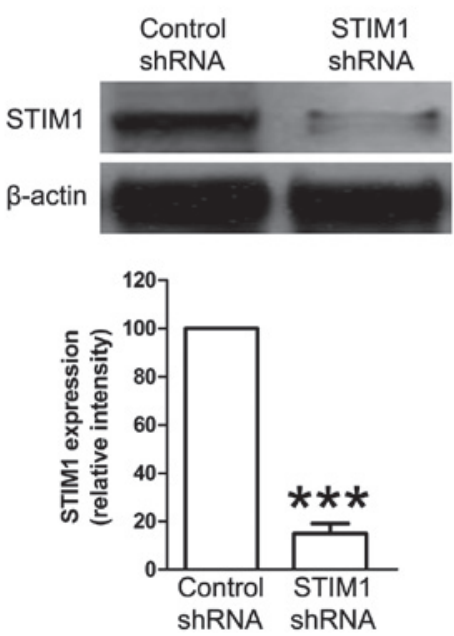
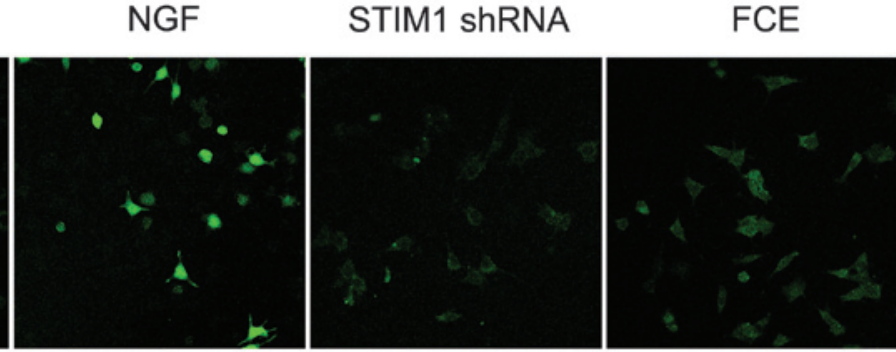

C
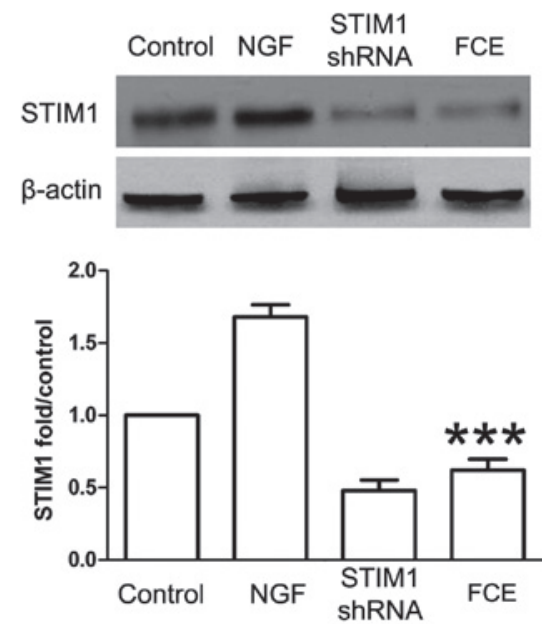

Figure 4. FCE treatment suppresses the expression of STIM1 protein in PC12 cells. (A) Expression of STIM1 protein in the PC12 cells of different groups (control, $50 \mathrm{ng} / \mathrm{ml} \mathrm{NGF-treated,} \mathrm{STIM1} \mathrm{shRNA-treated} \mathrm{and} 60 \mu \mathrm{g} / \mathrm{ml}$ FCE-treated groups) was observed through immunofluorescence staining. Scale bar, $100 \mu \mathrm{m}$. (B) PC12 cells were treated with STIM1 shRNA or control shRNA, and the expression of STIM1 protein was detected by western blotting with specific anti-STIM1 antibody. Data are expressed as mean \pm standard error of the mean (SEM). ${ }^{* * * *} \mathrm{P}<0.001$ compared with the control group. (C) The expression of STIM1 protein in PC12 cells of different groups was detected by western blotting, and assessed by semi-quantitative analysis. All experiments were conducted in triplicate. Data are expressed as mean \pm SEM. ${ }^{* * * *} \mathrm{P}<0.001$ compared with the untreated control. FCE, Fructus Corni extract; NGF, nerve growth factor; STIM1, stromal interaction molecule 1; shRNA, short hairpin RNA.

A

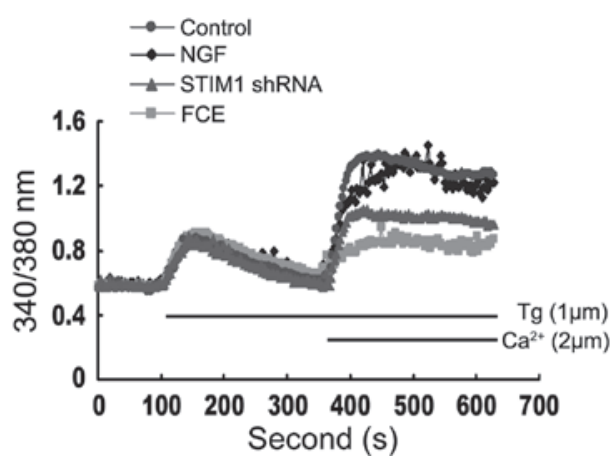

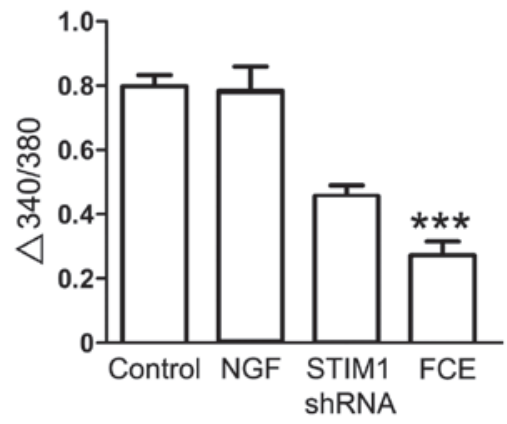

Figure 5. FCE-induced neurite growth in PC12 cells is associated with the inhibition of $\mathrm{Ca}^{2+}$ influx. (A) Cytosolic $\mathrm{Ca}^{2+}$ was measured in the PC12 cells of different groups (control, $50 \mathrm{ng} / \mathrm{ml}$ NGF-treated, STIM1 shRNA-treated and $60 \mu \mathrm{g} / \mathrm{ml} \mathrm{FCE-treated} \mathrm{groups),} \mathrm{and} \mathrm{representative} \mathrm{traces} \mathrm{of} \mathrm{intracellular} \mathrm{Ca}{ }^{2+}$ changes (fluorescence emission at $505 \mathrm{~nm}$ with alternating excitation wavelengths of 340 and $380 \mathrm{~nm}$ ) in PC12 cells were observed. (B) Involvement of inhibiting extracellular $\mathrm{Ca}^{2+}$ influx in FCE-induced neurite growth of PC12 cells. Fluorescence emission at $505 \mathrm{~nm}$ was monitored while excitation wavelengths were alternated between 340 and $380 \mathrm{~nm}$ at a frequency of $0.5 \mathrm{~Hz}$ The intracellular $\mathrm{Ca}^{2+}$ measurements were determined as a $340 / 380 \mathrm{~nm}$ ratio obtained from different groups. All data shown are from individual experiments representative of at least three independent replicates. Data are expressed as mean \pm standard error of the mean. " $\mathrm{P}<0.001$ compared with the untreated control. FCE, Fructus Corni extract; NGF, nerve growth factor; STIM1, stromal interaction molecule 1; shRNA, short hairpin RNA.

$\mathrm{Ca}^{2+}$-regulated proteins and the corresponding signaling pathways. There are two main sources of intracellular free $\mathrm{Ca}^{2+}$ : $\mathrm{Ca}^{2+}$ released from intracellular $\mathrm{Ca}^{2+}$ storage organelles, most notably the ER, and $\mathrm{Ca}^{2+}$ influx from sources external to the cell (17). It has been recognized that $\mathrm{Ca}^{2+}$ influx into neuronal subcellular compartments (for example, dendrites, somata, spines and axons) is mediated by two principal means of $\mathrm{Ca}^{2+}$ entry. These routes are voltage-gated $\mathrm{Ca}^{2+}$ channels (VGCCs) and ionotropic neurotransmitter receptors; both routes elicit crucial rises in cytosolic $\mathrm{Ca}^{2+}$ levels in response to different stimuli (18). VGCCs are widely expressed in excitable cells and they trigger $\mathrm{Ca}^{2+}$ influx over specific ranges of membrane 
potentials (19). Neurons along with other cell types display an alternative $\mathrm{Ca}^{2+}$ entry mode that is coupled to intracellular $\mathrm{Ca}^{2+}$ stores. This alternative type of entry, known as capacitative $\mathrm{Ca}^{2+}$ entry, is triggered upon the depletion of $\mathrm{Ca}^{2+}$ stores to facilitate SOCE (20). SOCE is a major mechanism by which $\mathrm{Ca}^{2+}$ is imported from extracellular to intracellular space. In general, the stimulation of cell surface receptors leads to the activation of IP3, which evokes a rapid and transient release of $\mathrm{Ca}^{2+}$ from the ER store through IP3 receptor channels. The resulting reduction of $\mathrm{Ca}^{2+}$ concentration in the ER is detected by the EF-hand motif of STIMs. This causes the STIMs to translocate to the plasma membrane, where they interact with Orai (also known as CRACM1) $\mathrm{Ca}^{2+}$ channel subunits, resulting in an influx of $\mathrm{Ca}^{2+}$ from the extracellular space in order to restore the $\mathrm{Ca}^{2+}$ concentration in the ER (21).

The essential roles of STIM1 and Orail in SOCE have been confirmed in a number of studies. STIM1 is a single-pass transmembrane protein in the ER membrane that functions as a $\mathrm{Ca}^{2+}$ sensor in the ER, while Orail is the pore-forming subunit of SOC channels in cell membranes (22). STIM1 predominantly exists in the sarcoplasmic reticulum (SR) or ER and has its $\mathrm{N}$-terminal sensing $\mathrm{Ca}^{2+}$ domain in the SR/ER lumen and its C-terminal Orail coupling site in the cytosol (23). STIM1 acts as both an ER $\mathrm{Ca}^{2+}$ sensor and activator of SOCE. When $\mathrm{Ca}^{2+}$ in the ER is depleted and STIM1 migrates to the plasma membrane, STIM1 forms aggregates at plasma membrane sites of $\mathrm{Ca}^{2+}$ entry, where it interacts with and activates Orail channels to induce SOCE (24). Several studies have investigated the potential involvement of SOCE-mediated $\mathrm{Ca}^{2+}$ metabolism with a focus on STIM1. For example, STIM proteins and Orai channels have been indicated to be associated with neuronal development and memory, and it has been shown that abnormal SOCE may participate in the $\mathrm{Ca}^{2+}$ overload of neurons in the early stages following diffuse axonal injury via an increase in STIM1 expression (25). In addition, it has been observed that STIM1- and Orai1-regulated SOCE is associated with changes in the proliferation of endothelial cells (26). In vascular smooth muscle cells, the knockdown of either STIM1 or Orai1 has been demonstrated to inhibit the proliferation and migration of the cells (27). Furthermore, STIM1-knockdown inhibited serum-induced epidermoid carcinoma cell migration (28). The data from the present study demonstrate that STIM1 plays an important role in FCE-induced neuritogenesis, suggesting that inhibiting STIM1-mediated SOCE-associated $\mathrm{Ca}^{2+}$ metabolism dysfunction might be a strategy for the treatment of neuronal injury.

The upstream pathway leading to SOCE in PC12 cells has not been elucidated. $\mathrm{Ca}^{2+}$ levels in the ER are mainly controlled by the phospholipase C (PLC)/IP3/IP3 receptor pathway with activation by tyrosine kinase-type or Gq-related $\mathrm{G}$ protein-coupled receptors (29). In colorectal cancer cells, SOCE has been shown to be controlled by tyrosine kinase-type receptors rather than by Gq-coupled receptors (30). In pulmonary arterial smooth muscle cells, platelet-derived growth factor was found to activate SOCE via Akt signaling (31). In addition, the phosphorylation of STIM1 at extracellular signal-regulated kinase 1/2 (ERK1/2) target sites has been demonstrated to regulate the association of STIM1 with EB1 (end-binding protein 1), a regulator of growing microtubule ends (32). Another study revealed that ERK1/2 phosphory- lates STIM1 in vitro at Ser575, Ser608 and Ser621, and that STIM1 regulates SOCE in HEK293 cells via phosphorylation at ERK1/2 target sites (33). An investigation of the functional association among tyrosine kinase-type receptors, SOCE and ERK signaling in PC12 cells would be of interest.

In conclusion, the findings of the present study provide the first evidence of induction of neurite outgrowth in PC12 cells by the traditional Chinese herbal medicine FCE. Additionally, the results demonstrate that FCE-induced neuritogenesis is associated with the suppression of STIM1 expression and the inhibition of $\mathrm{Ca}^{2+}$ influx. These results provide a useful information regarding the therapeutic potential of FCE for the treatment of neurodegenerative disease.

\section{References}

1. Soboloff J, Rothberg BS, Madesh M and Gill DL: STIM proteins: dynamic calcium signal transducers. Nat Rev Mol Cell Biol 13: 549-565, 2012.

2. Stathopulos PB, Schindl R, Fahrner M, et al: STIM1/Orai1 coiled-coil interplay in the regulation of store-operated calcium entry. Nat Commun 4: 2963, 2013.

3. Jozsef L, Tashiro K, Kuo A, et al: Reticulon 4 is necessary for endoplasmic reticulum tubulation, STIM1-Orai1 coupling and store-operated calcium entry. J Biol Chem 289: 9380-9395, 2014.

4. Pozo-Guisado E and Martin-Romero FJ: The regulation of STIM1 by phosphorylation. Commun Integr Biol 6: e26283, 2013.

5. Ross DG, Smart CE, Azimi I, Roberts-Thomson SJ and Monteith GR: Assessment of ORAI1-mediated basal calcium influx in mammary epithelial cells. BMC Cell Biol 14: 57, 2013.

6. Zhang H, Clemens RA, Liu F, et al: STIM1 calcium sensor is required for activation of the phagocyte oxidase during inflammation and host defense. Blood 123: 2238-2249, 2014.

7. Harraz OF and Altier C: STIM1-mediated bidirectional regulation of $\mathrm{Ca}^{2+}$ entry through voltage-gated calcium channels (VGCC) and calcium-release activated channels (CRAC). Front Cell Neurosci 8: 43, 2014.

8. Lee KP, Choi S, Hong JH, et al: Molecular determinants mediating gating of transient receptor potential canonical (TRPC) channels by stromal interaction molecule 1 (STIM1). J Biol Chem 289: 6372-6382, 2014.

9. Poon TY, Ong KL and Cheung BM: Review of the effects of the traditional chinese medicine rehmannia six formula on diabetes mellitus and its complications. J Diabetes 3: 184-200, 2011.

10. Cai H, Cao G and Cai B: Rapid simultaneous identification and determination of the multiple compounds in crude Fructus Corni and its processed products by HPLC-MS/MS with multiple reaction monitoring mode. Pharm Biol 51: 273-278, 2013.

11. Chu Q, Amano O, Kanda Y, Kunii S, Wang Q and Sakagami H: Tumor-specific cytotoxicity and type of cell death induced by gefitinib in oral squamous cell carcinoma cell lines. Anticancer Res 29: 5023-5031, 2009.

12. Wu Y, Wang X, Shen B, Kang L and Fan E: Extraction, structure and bioactivities of the polysaccharides from Fructus Corni. Recent Pat Food Nutr Agric 5: 57-61, 2013.

13. Wang W, Xu J, Li L, et al: Neuroprotective effect of morroniside on focal cerebral ischemia in rats. Brain Res Bull 83: 196-201, 2010.

14. Hong SY, Jeong WS and Jun M: Protective effects of the key compounds isolated from Corni fructus against $\beta$-amyloid-induced neurotoxicity in PC12 cells. Molecules 17: 10831-10845, 2012.

15. Livak KJ and Schmittgen TD: Analysis of relative gene expression data using real-time quantitative PCR and the $2\left(-\Delta \Delta \mathrm{C}_{\mathrm{T}}\right)$ method. Methods 25: 402-428, 2001.

16. Liao Y, Plummer NW, George MD, et al: A role for Orai in TRPC-mediated $\mathrm{Ca} 2+$ entry suggests that a TRPC:Orai complex may mediate store and receptor operated $\mathrm{Ca} 2+$ entry. Proc Natl Acad Sci USA 106: 3202-3206, 2009.

17. Smyth JT and Putney JW: Regulation of store-operated calcium entry during cell division. Biochem Soc Trans 40: 119-123, 2012.

18. Cahalan MD: STIMulating store-operated $\mathrm{Ca}^{2+}$ entry. Nat Cell Biol 11: 669-677, 2009. 
19. Kilch T, Alansary D, Peglow M, et al: Mutations of the $\mathrm{Ca}^{2+}$-sensing stromal interaction molecule STIM1 regulate $\mathrm{Ca}^{2+}$ influx by altered oligomerization of STIM1 and by destabilization of the $\mathrm{Ca}^{2+}$ channel Orai1. J Biol Chem 288: 1653-1664, 2013.

20. Umemura M, Baljinnyam E, Feske S, et al: Store-operated $\mathrm{Ca}^{2+}$ entry (SOCE) regulates melanoma proliferation and cell migration. PLoS One 9: e89292, 2014.

21. Smyth JT and Putney JW: Regulation of store-operated calcium entry during cell division. Biochem Soc Trans 40: 119-123, 2012.

22. Johnstone LS, Graham SJ and Dziadek MA: STIM proteins: integrators of signalling pathways in development, differentiation and disease. J Cell Mol Med 14: 1890-1903, 2010.

23. Liu H, Hughes JD, Rollins S, Chen B and Perkins E: Calcium entry via ORAI1 regulates glioblastoma cell proliferation and apoptosis. Exp Mol Pathol 9: 753-760, 2011.

24. Chiu TY, Teng HC, Huang PC, Kao FJ and Yang DM: Dominant role of Orail with STIM1 on the cytosolic entry and cytotoxicity of lead ions. Toxicol Sci 110: 353-362, 2009.

25. Li Y, Song J, Liu X, Zhang M, et al: High expression of STIM1 in the early stages of diffuse axonal injury. Brain Res 1495: 95-102, 2013.

26. Abdullaev IF, Bisaillon JM, Potier M, Gonzalez JC, Motiani RK and Trebak M: Stim1 and Orail mediate CRAC currents and store-operated calcium entry important for endothelial cell proliferation. Circ Res 103: 1289-1299, 2008.

27. Potier M, Gonzalez JC, Motiani RK, et al: Evidence for STIM1and Orail-dependent store-operated calcium influx through ICRAC in vascular smooth muscle cells: role in proliferation and migration. FASEB J 23: 2425-2437, 2009.
28. Yoshida J, Iwabuchi K, Matsui T, Ishibashi T, Masuoka T and Nishio M: Knockdown of stromal interaction molecule 1 (STIM1) suppresses store-operated calcium entry, cell proliferation and tumorigenicity in human epidermoid carcinoma A431 cells. Biochem Pharmacol 84: 1592-1603, 2012.

29. Pozo-Guisado E, Campbell DG, Deak M, et al: Phosphorylation of STIM1 at ERK1/2 target sites modulates store-operated calcium entry. J Cell Sci 123: 3084-3093, 2010.

30. Wang JY, Chen BK, Wang YS, et al: Involvement of store-operated calcium signaling in EGF-mediated COX-2 gene activation in cancer cells. Cell Signal 24: 162-169, 2012.

31. Ogawa A, Firth AL, Smith KA, Maliakal MV and Yuan JX: PDGF enhances store-operated $\mathrm{Ca}^{2+}$ entry by upregulating STIM1/Orai1 via activation of Akt/mTOR in human pulmonary arterial smooth muscle cells. Am J Physiol Cell Physiol 302: C405-C411, 2012.

32. Pozo-Guisado E, Casas-Rua V, Tomas-Martin P, LopezGuerrero AM, Alvarez-Barrientos A and Martin-Romero FJ: Phosphorylation of STIM1 at ERK1/2 target sites regulates interaction with the microtubule plus-end binding protein EB1. J Cell Sci 126: 3170-3180, 2013.

33. Fedida-Metula S, Feldman B, Koshelev V, Levin-Gromiko U, Voronov E and Fishman D: Lipid rafts couple store-operated $\mathrm{Ca}^{2+}$ entry to constitutive activation of PKB/Akt in a $\mathrm{Ca}^{2+} /$ calmodulin-, Src- and PP2A-mediated pathway and promote melanoma tumor growth. Carcinogenesis 33: 740-750, 2012. 